\title{
THE MEDIATING IMPACT OF BELIEFS ON THE RELATIONSHIP BETWEEN VALUES AND PERCEPTION IN EVENT GREENING
}

\author{
Nor Lela Ahmad \\ Faculty of Business and Management, MARA University of Technology, Malaysia; \\ norlela7676@gmail.com \\ Nik Hasnaa Nik Mahmood \\ Razak School of UTM in Engineering and Advanced Technology, Malaysia; \\ nikhasnaa.kl@utm.my \\ Mohd. Hanafi Azman Ong \\ Faculty of Business and Management, MARA University of Technology, Malaysia; \\ napieong@yahoo.com
}

\begin{abstract}
The issue of sustainability is a global concern. There is a lack of knowledge about the perception towards the green concept and going green in Malaysia especially in the event management field of study. This study investigates the effect of values, beliefs and norms towards the perception of sustainable efforts towards event greening from event attendees' point of view in the event management context. The objectives of this study are to determine the level of values, beliefs and norms that affect the perception of sustainable efforts towards event greening; to establish that event attendees' values influence their perception on sustainable efforts towards event greening; to measure the mediation effect of beliefs in the relationship between values and perception on sustainable efforts towards event greening; to measure the mediation effect of norms in the relationship between values and perception on sustainable efforts towards event greening; to identify that cost is a concern to implement sustainable efforts towards event greening and to identify the reasons that event organizers are not keen to implement sustainable efforts towards event greening. Building from the perspective of event management, Value-Belief-Norm Theory, Theory of Planned Behaviour and Reflexive Theory of Perception; a conceptual model is developed and the hypotheses are drawn to show the interrelationship between these constructs. The partial least square (PLS) statistical approach has been conducted to test the research hypotheses. The analysis indicated that, there is a full mediating effect of Beliefs and Norms towards the relationship between Values and Perception.
\end{abstract}

Keywords: values, beliefs, perception, sustainability, event greening

\section{Introduction}

Environmental sociologists have developed numerous theories in attempts to determine the predictors of Environmentally Significant Behavior. In this study, Value-Belief-Norm (VBN) theory was modified and employed as a conceptual framework in order to assess VBN theory, as well as expand it to incorporate social context. This theory was an advancement in the research that combines elements that were previously investigated separately. Developed by Paul Stern and his colleagues through a series of studies, VBN theory combines three theories used in prior research to create a more comprehensive model (Stern, 2000). The VBN model originated from a theoretical model linking support for environmental protection to social-psychological factors.

Values are defined as abstract ideals a person holds for society. Beliefs are defined as opinions and cognitions regarding the world. Lastly, personal norms are defined as feelings of personal obligation people experience that "impel individuals" to behave in ways supporting their values and beliefs. In order to fully understand VBN theory, a brief description of the three theoretical aspects that Stern synthesized is necessary. Value theory refers to the effect that the values of altruism (e.g. social justice and equality), conservation (e.g. tradition, conformity, and security), self-interest (e.g. wealth, 
dominance, and social power), and openness to change (e.g. stimulation and achievement) have on environmental concern (Ha \& Janda, 2012).

Later, Stern and his colleagues incorporated some components about human-environment relations into VBN theory, as a part of the model's belief components. The last component of VBN theory consists of personal norms that are activated by the beliefs component. Previous studies have focused on values, environmental concern, beliefs, feelings of responsibility, norms and other social contextual factors (Nordlund and Garvill 2002). VBN theory combines many of the concepts that researchers had been investigating independently. A modified version of Stern "s VBN theory was utilized to model this study's predictions.

Fishbein and Ajzen (1975) propose a relationship that links beliefs, attitude, intentions, and behaviors. Beliefs influence a consumer's overall attitude about an object. Beliefs often reflect commonly available evidence about product characteristics that helps enhance people's psychological comfort. However, we argue that specific beliefs about consequences of energy-efficient products will affect specific attitudes toward use of an environmentally friendly product rather than general beliefs about a concern for the environment (Tanner and Kast, 2003). Beliefs are based on knowledge, or that which the individual perceives to be true. Research in the decision- making realm has defined confidence as an individual's belief that his/her judgment is accurate or that future events will occur as expected (Siegrist et al., 2003). As noted previously, both belief and confidence are psychologically classified as similar perceptions, but the degree of confidence reflects how sure the consumer is that the product addresses a genuine issue (McDonald and Oates, 2006). It represents an environmental benefit in this context. The literature provides different lists of the characteristics that define green consumers. Some authors distinguish four types of consumer characteristics such as demographic, socio-economic, psychographic, and behavioral (Kotler et al., 2005), while others denote five types - demographic, knowledge, values, attitudes, and behavior. Still others name habits, personal capabilities, values, beliefs and norms as the most important green consumer characteristics (Ćekanavičius, 2014).

Consumer buyer behavior namely: cultural factors (includ ing culture, subculture and social class); social factors (namely, reference groups, family, and roles and status); personal factors (e.g. age and life cycle stage, occupation, economic situation, lifestyle, personality and self-concept); and psychological factors (motivation, perception, learning, and beliefs and attitudes). There have been studies indicating a positive relationship between attitude and behavior. Specific consumer beliefs predict environmentally friendly consumer behavior more accurately than does general environmental concern. Additionally, the study by Laroche, Bergeron and Barbaro-Forleo (2001) strongly showed that pro-environmental attitude is positively related to consumer willingness to pay more for environmentally friendly products (Eze \& Ndubisi, 2013).

The consumer's purchasing choices express not only price and quality preferences but also social norms, values and individual beliefs. Less empirical evidence exists to support that pro-environmental attitudes and beliefs translate into environmentally conscious behaviours such as green buying. The collectivistic orientations influence beliefs of consumer effectiveness, which in turn influence green buying (Liu, Wang, Shishime, \& Fujitsuka, 2012). Rationality refers to the logic behind individual behaviors based on their values and beliefs (Cropanzano \& Mitchell, 2005). Values and beliefs influence their perceptions. Several studies have examined the effects of environmental attitudes and values on the perceptions toward tourism development. The rationality rule refers to the effects of the beliefs and values on perceptions (Rasoolimanesh, Jaafar, Kock, \& Ramayah, 2015).

Svensson and Wagner (2011) link driving forces, such as the power of the media, lobby groups, government legislation, and institutional responsibilities, to the development of organizational values, norms and beliefs, that in turn affect how management, staff and other stakeholders practice their businesses. This issue is related to sustainability practices and socially responsible managers manage sustainable business practices because they believe that it is the right thing to do, and that the code of ethics, or ethical culture, plays a major part in enhancing the ethical performance of organizations, and "corporate efforts" to manage and monitor sustainable business practices from an ethical perspective. The code of ethics, embracing dimensions such as values, norms and beliefs, appears as a core construct in previous research points to the importance of values, ideologies, and beliefs, when hindering or fostering the implementation of sustainable practices. A similar concept, as compared to 
code of ethics - or culture - is the concept of "ethos", which according to Oxford Advanced Learner's Dictionary is "characteristic spirit, moral, values, ideas or beliefs of a group, community or culture" (Mysen, 2012)

Based on the findings of the literature review, this study proposed a conceptual framework between the concepts of Value, Belief, and Perception of Attendees on Sustainable Effort towards Event Greening (i.e. Figure 1). Hence, this study intends to investigate the effect of Belief as a mediator between the relationship of Value and Perception of Attendees on Sustainable Effort towards Event Greening.

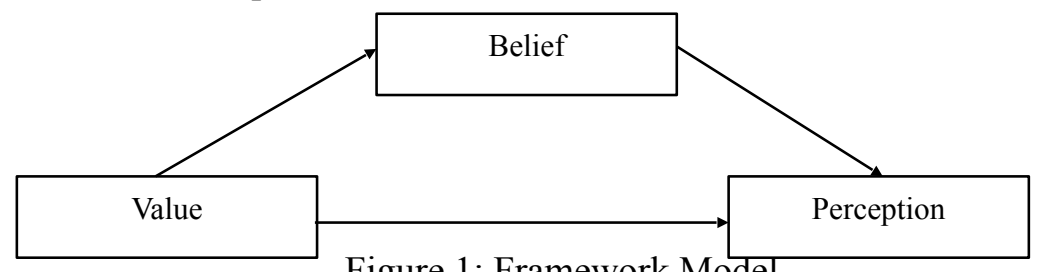

Figure 1: Framework Model

\section{Methodology}

Survey methodology with the combination of quantitative method was used for conducting this research. It is because both methodologies allow the researcher to examining the causal relationship among the variables (Saunders, Lewis, and Thornhill, 2009). Instruments with the structured questions was used to measure the variables and it was distributed to the 405 respondents who are above 18 years old that attends specific green events in Malaysia for the past three months.

The PLS-SEM technique was used to explore the relationship among the targeted variables that was proposed in the framework above (Hair et al, 2014 and Ong and Puteh, 2017). Latent variable score (i.e. LVS) technique was employed in this analysis since the Value variable was measures using the concept of higher order construct (i.e. HOC) (Henseler and Chin, 2010). The 5000 replications of samples (i.e. bootstrapping) were used for measuring the significance of the structural path in this model (Hair, Ringle, and Sarstedt, 2011). The Bias Corrected Accelerated Bootstrap (i.e. BCa) confidence level was used as well as empirical t-statistics for measuring the significant path mediating effect (Hair, Ringle, and Sarstedt, 2011, and Ong and Puteh, 2017).

Besides that, in order to measure the effect of mediating, the following procedure for deciding the mediating effect was used (Zhao, Lynch, and Chen, 2010) and (Iacobucci, Saldanha, and Deng, 2007). The procedures are:

1) If the path of independent variable to dependent variable was not significant and the indirect effect is significant, hence the mediating effect was a full mediation effect.

2) If the path of independent variable to dependent variable was significant and the indirect effect is significant, hence the mediating effect was a partial mediation effect.

\section{Results and Discussion}

\section{First Order Measurement Model}

Convergent and discriminant validities were performed for assessing the quality of the first measurement model ${ }^{2}$. Table 1 indicated that, all indicators has passed the minimum requirement of convergent validity, where factor loading was above .70 and statistically significant, each AVE value was above .50 , and also the Composite reliability and Cronbach's Alpha were also above .70. In addition, HTMT discriminant analysis (i.e. Table 2) confirms the discriminant validity of this measurement since all the values were less than $.85^{8}$.

Table 1: Convergent Validity for first order measurement model

\begin{tabular}{cccccc}
\hline LV & Indicator & $\gamma$ & AVE & $\rho$ & $\alpha$ \\
\hline AV1 & $.855^{*}$ & &
\end{tabular}




\begin{tabular}{|c|c|c|c|c|c|}
\hline \multirow{3}{*}{ Altruistic } & AV2 & $.852 *$ & \multirow{3}{*}{.726} & \multirow{3}{*}{.914} & \multirow{3}{*}{.874} \\
\hline & AV3 & $.849 *$ & & & \\
\hline & AV4 & $.852 *$ & & & \\
\hline \multirow{4}{*}{ Biospheric } & BV1 & $.893 *$ & \multirow{4}{*}{.786} & \multirow{4}{*}{.936} & \multirow{4}{*}{.909} \\
\hline & BV2 & $.901 *$ & & & \\
\hline & BV3 & $.865^{*}$ & & & \\
\hline & BV4 & $.886^{*}$ & & & \\
\hline \multirow{4}{*}{ Egoistic } & EV1 & $.806^{*}$ & \multirow{4}{*}{.664} & \multirow{4}{*}{.887} & \multirow{4}{*}{.830} \\
\hline & EV2 & $.734^{*}$ & & & \\
\hline & EV3 & $.857^{*}$ & & & \\
\hline & EV4 & $.857^{*}$ & & & \\
\hline \multirow{5}{*}{ Nature Preservation } & EW1 & $.724^{*}$ & \multirow{5}{*}{.565} & \multirow{5}{*}{.867} & \multirow{5}{*}{.807} \\
\hline & EW2 & $.773 *$ & & & \\
\hline & EW7 & $.778^{*}$ & & & \\
\hline & EW8 & $.772 *$ & & & \\
\hline & EW9 & $.711 *$ & & & \\
\hline \multirow{3}{*}{ Human Adaptability } & EW3 & $.818^{*}$ & \multirow{3}{*}{.561} & \multirow{3}{*}{.793} & \multirow{3}{*}{.715} \\
\hline & EW4 & $.702 *$ & & & \\
\hline & EW11 & $.728^{*}$ & & & \\
\hline \multirow{6}{*}{ Perception } & PS1 & $.738^{*}$ & \multirow{6}{*}{.591} & \multirow{6}{*}{.896} & \multirow{6}{*}{.861} \\
\hline & PS2 & $.809 *$ & & & \\
\hline & PS3 & $.771^{*}$ & & & \\
\hline & PS4 & $.735^{*}$ & & & \\
\hline & PS5 & $.823^{*}$ & & & \\
\hline & PS6 & $.732 *$ & & & \\
\hline
\end{tabular}

Note: $\mathrm{LV}=$ Latent Variable; $\gamma=$ Factor Loading; AVE $=$ Average Variance Extracted; $\rho=$ Composite Reliability; $\alpha=$ Cronbach's Alpha; * $\mathrm{p}<.01$.

Table 2: HTMT discriminant validity for the first order measurement model

\begin{tabular}{c|cccccc}
\hline LV & $(1)$ & $(2)$ & $(3)$ & $(4)$ & $(5)$ & $(6)$ \\
\hline$(1)$ & - & & & & & \\
$(2)$ & .797 & - & & & \\
$(3)$ & .534 & .457 & - & & \\
$(4)$ & .620 & .530 & .696 & - &. & \\
$(5)$ & .481 & .333 & .610 & .644 & .338 & - \\
$(6)$ & .492 & .386 & .358 & .556 & .338
\end{tabular}

Note: LV = Latent Variable; (1) = Altruistic; (2) = Biospehric; (3) = Egoistic; (4) = Nature 
Preservation; (5) = Human Adaptability; (6) = Perception.

\section{Second Order Measurement Model}

Table 3 indicated that, all indicators for measuring the latent variables were above the minimum threshold loading of .70. In addition, the AVE values for each latent variable in this measurement model were also above the threshold value of 0.50 , as well as the Composite reliability and Cronbach's Alpha were also above .70. In terms of discriminant validity, the analysis (i.e. Table 4) confirms the existing of the discriminant validity (Henseler, Ringle, and Sarstedt, 2015). Therefore, the structural model and mediating testing can be evaluated.

Table 3: Convergent Validity for second order measurement model

\begin{tabular}{cccccc}
\hline LV & Indicator & $\gamma$ & AVE & $\rho$ & $\alpha$ \\
\hline \multirow{3}{*}{ Value } & Altruistic & $.879^{*}$ & & & \\
& Biospheric & $.832^{*}$ & .684 & .866 & .768 \\
Egoistic & $.766^{*}$ & & & \\
\hline \multirow{2}{*}{ Belief } & Nature Preservation & $.916^{*}$ & \multirow{2}{*}{.729} & .843 & .743 \\
& Human Adaptability & $.787^{*}$ & & & \\
\hline & PS1 & $.738^{*}$ & & & \\
PS2 & $.813^{*}$ & & & \\
& PS3 & $.772^{*}$ & & & \\
& PS4 & $.727^{*}$ & .591 & .896 & \\
& PS5 & $.821^{*}$ & & & \\
& PS6 & $.736^{*}$ & & &
\end{tabular}

Note: $\mathrm{LV}=$ Latent Variable; $\gamma=$ Factor Loading; AVE = Average Variance Extracted; $\rho=$ Composite Reliability; $\alpha=$ Cronbach's Alpha; ${ }^{\text {TThis }}$ is a reversed coded item; ${ }^{*} \mathrm{p}<.01$.

Table 4: HTMT discriminant validity for the second order measurement model

\begin{tabular}{c|ccc}
\hline LV & $(1)$ & $(2)$ & $(3)$ \\
\hline$(1)$ & - & & \\
$(2)$ & .793 & - & - \\
$(3)$ & .533 & .558 & - \\
\hline
\end{tabular}

Note: LV = Latent Variable; (1) = Value; (2) = Belief; (3) = Perception.

\section{Structural Model and Mediating Testing}

The total variation explained $\left(R^{2}\right)$ for Belief and Perception were .413 and .234. It is indicated that, Value was able to explain about $41.3 \%$ towards Belief, whereas in the simultaneous concept, Value and Belief were applicable to explained about $23.4 \%$ of variance explained. In addition, the assessment of effect size $\left(f^{2}\right)$ and predictive relevance $\left(q^{2}\right)$ for each path can be considered as weak to large effect ${ }^{2}$ (i.e. Table 5).

Table 5: Effect size $\left(f^{2}\right)$ and Predictive Relevance $\left(q^{2}\right)$

\begin{tabular}{ccccc}
\hline & $f^{2}$ & Remark & $q^{2}$ & Remark \\
\hline Value $\rightarrow$ Belief & .704 & Large & .425 & Large
\end{tabular}




$$
\begin{aligned}
& \text { Value } \rightarrow \text { Perception } \\
& \text { Belief } \rightarrow \text { Perception }
\end{aligned}
$$

.054

.162
Weak

Moderate
.071

.109
Weak

Moderate

The assessment of path coefficient indicated that, Value have positive significant effect toward Belief $(\ddot{B}=0.643, \mathrm{t}=18.275, \mathrm{p}<.01)$ and Perception $\left(\vec{B}^{\circ}=0.264, \mathrm{t}=4.257, \mathrm{p}<.01\right)$. Besides that, the analysis also indicated that, Belief also have a positive significant effect Perception $(\ddot{F}=0.270, \mathrm{t}=4.609, \mathrm{p}<$. 01). Therefore, it is indicated that, if the average level of Value was high, then the levels of Belief and Perception will be also high. In the same way, if the average level of Belief was high, then the levels of Perception will be also high.

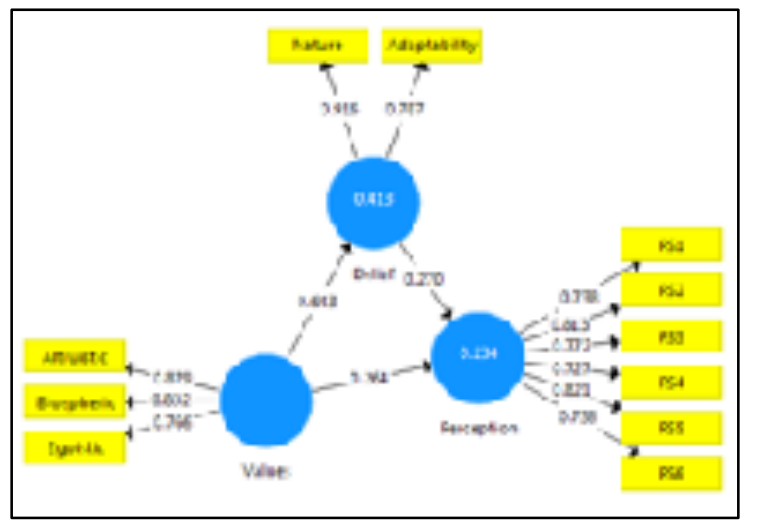

Figure 2: Loading Assessment of PLS-SEM

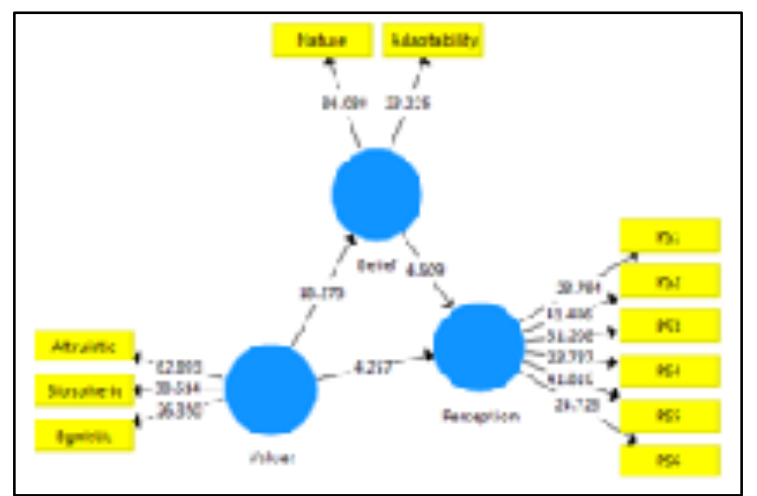

Figure 3: Bootstrap Assessment of PLS-SEM

\section{Mediating Testing}

The indirect effect assessment confirms that, Belief mediated the relationship of Value and Perception. It is because the indirect path of VA $\rightarrow \mathrm{BE} \rightarrow \mathrm{PE}$ was significant (Indirect effect Coefficient $=0.173, t$ $=4.326, p<.01)$ and this result was supported by the bootstrapping analysis, where the $95 \%$ confidence level was not including zero (BCa Bootstrap: 0.100, 0.252). The effect of the Beliefs toward the relationship of Value and Perception can be categorized as partial mediating effect since the direct effect of Value toward Perception was significant $(\ddot{\vec{B}}=0.264, t=4.257, p<.01)$.

Table 7: Indirect Effect Assessment

\begin{tabular}{cccc}
\hline Path & IEC & t-value & BCa Bootstrap \\
\hline $\mathrm{VA} \rightarrow \mathrm{BE} \rightarrow \mathrm{PE}$ & 0.173 & $4.326^{*}$ & $(0.100,0.252)$
\end{tabular}

Note: $\mathrm{VA}=$ Value; $\mathrm{BE}=$ Belief; $\mathrm{PE}=$ Perception; $\mathrm{IEC}=$ Indirect Effect Coefficient; the result of $\mathrm{BCa}$ Bootstrap was based on $95 \%$ bootstrap confidence interval with 5000 replication; ${ }^{*} \mathrm{p}<.01$. 


\section{Conclusion}

The quantitative results indicated that there is an association between values, beliefs, norms and perception of sustainable efforts towards event greening. Therefore, it can be concluded that, if the average level of Values were good, then the average value of Beliefs and also Norms will be high. However, the increases or decrease in the level of Values, did not give a significant effect toward Perception level. The analysis indicated that, there is a full mediating effect of Beliefs and Norms towards the relationship between Values and Perception.

This study recommends that event organizers should encourage Malaysian event attendees to support the implementation of sustainable efforts towards event greening in order to contribute to environmental well-being by re-evaluating the values, beliefs and norms in their daily lives. The relevant authorities should continuously provide support in environmental preservation activities such as promoting the implementation of sustainable efforts towards event greening in the event management industry.

\section{Acknowledgment}

The authors would like to express the deepest appreciation to all those who provided us the possibility to complete this research. The co-operation is much indeed appreciated. The authors also gratefully acknowledge the contribution of the Research Management Centre of Universiti Teknologi MARA, for the ongoing support and efficient management of the Fundamental Research Grant Scheme provided by the Malaysia Education Ministry [(600-IRMI/DANA 5/3/AAGBS (006/2017)], which contributed greatly to the quality of this study and outcomes. Their contribution for making the research proposal process smooth and efficient is highly appreciated.

\section{References}

Cekanavičius, L. (2014). Green Business : Challenges and Practices, 93(1), 74-88.

Cropanzano, R., and M. Mitchell. 2005. "Social Exchange Theory: An Interdisciplinary Review." Journal of Management 31 (6): 874-900.

Eze, U. C., \& Ndubisi, N. O. (2013). Green Buyer Behavior: Evidence from Asia Consumers. Journal of Asian and African Studies, 48(4), 413-426.

Fishbein, M. \& Ajzen, I. (1975). Belief, attitude, intention and behavior: An Introduction to theory and research. Reading, MA: Addison-Wesley.

Ha, H., \& Janda, S. (2012). Predicting consumer intentions to purchase energy-efficient products. Journal of Consumer Marketing, 29(7), 461-469.

Hair, J.F, Hult, G.T.M., Ringle, C.M., Sarstedt, M. (2014). A Primer on Partial Least Squares Structural Equation Modeling (PLS-SEM). Thousand Oaks: SAGE Publications.

Hair, J.F., Ringle, C.M., \& Sarstedt, M. (2011). PLS-SEM: Indeed a silver bullet. Journal of Marketing Theory and Practice, Vol. 19 (2), 139-151.

Henseler, J., Ringle, C. M., \& Sarstedt, M. (2015). A new criterion for assessing discriminant validity in variance-based structural equation modeling. Journal of the Academy Marketing Science, 43(1), $115-135$.

Henseler, J., \& Chin, W. W., (2010). A comparison of approaches for the analysis of interaction effects between latent variables using partial least squares path modeling. Structural Equation Modeling 17 (1), 82-109.

Iacobucci, D., Saldanha, N., \& Deng, X. (2007). A meditation on mediation: Evidence that structural equation models perform better than regression. Journal of Consumer Psychology, Vol. 7(2), 140-154.

Kotler, P. (2005). Marketing Management. (11th Ed.). New Jersey: Prentice Hall.

Laroche, M., Bergeron, J. \& Barbaro-Forleo, G. (2001). Targeting consumers who are willing to pay more for environmentally friendly products. Journal of Consumer Marketing, 18(6), 503-520. 
Liu, X., Wang, C., Shishime, T., \& Fujitsuka, T. (2012). Sustainable consumption: Green purchasing behaviours of urban residents in China. Sustainable Development, 20, 293-308. McDonald, S. and Oates, C.J. (2006), "Sustainability: consumer perceptions and marketing strategies", Business Strategy and the Environment, Vol. 15 No. 3, pp. 157-70.

Mysen, T. (2012). Sustainability as corporate mission and strategy. European Business Review, 24(6), 496-509.

Nordlund, a. M., \& Garvill, J. (2002). Value Structures behind Proenvironmental Behavior. Environment and Behavior, 34(6), 740-756.

Ong, M.H.A., \& Puteh, F. (2017). Quantitative Data Analysis: Choosing Between SPSS, PLS, and AMOS in Social Science Research. International Interdisciplinary Journal of Scientific Research, Vol. 3 (1), 14-25.

Rasoolimanesh, S. M., Jaafar, M., Kock, N., \& Ramayah, T. (2015). A revised framework of social exchange theory to investigate the factors influencing residents' perceptions. Tourism Management Perspectives, 16, 335-345.

Saunders, M., Lewis, P., \&Thornhill, A. (2009). Research Method for Business Students (5th ed.). New York: Prentice Hall Publications.

Siegrist, M., Earle, T.C. and Gutscher, H. (2003), "Test of trust and confidence model in the applied context of electromagnetic", Risk Management, Vol.23No. 4, pp. 705-16.

Stern, P. C. (2000). Toward a coherent theory of environmentally significant behavior. Journal of Social Issues, 56(3), 407-424.

Svensson, G. and Wagner, B. (2011), "Transformative business sustainability: multi-layer model and network of e-footprint sources", European Business Review, Vol. 23 No. 4, pp. 334-52

Tanner, Carmen and SybilleW. Kast (2003), "Promoting Sustainable Consump- tion: Determinants of Green Purchases by Swiss Consumers," Psychology \& Marketing, 20 (10), 883-902.

Zhao, X., Lynch, J.G.J., \& Chen, Q. (2010). Reconsidering Baron and Kenny: Myths and truth about mediation analysis. Journal of Consumer Research, Vol. 17, 197-206. 